TABLE 1. INFLUENOE OF MANURING AND CROP ROTATION ON SOIL PROPERTIES.

\begin{tabular}{|c|c|c|c|c|c|c|c|c|}
\hline Treatment & $\begin{array}{c}\text { Depth } \\
\text { (in.) }\end{array}$ & $\begin{array}{c}\text { Clay + } \\
\text { fine silt } \\
\text { (per cent)* }\end{array}$ & $\begin{array}{c}\text { Pore space } \\
\text { (c.c.per } \\
100 \text { c.c.) } t\end{array}$ & $\begin{array}{c}\text { Volume- } \\
\text { weight } \\
\text { (gm. per } \\
100 \text { c.c.)t }\end{array}$ & $\begin{array}{c}\text { Moisture } \\
\text { content of } \\
\text { saturated soil } \\
\text { (per cent) } \dagger\end{array}$ & $\begin{array}{c}\text { Coefficient } \\
\text { of } \\
\text { structure }\end{array}$ & $\underset{(\text { per cent })^{*}}{\text { Carbon }}$ & $\frac{\text { Nitrogen }}{(\text { per cent) }}$ \\
\hline$\underset{\text { compost }}{\text { Farm }}$ & $\begin{array}{c}0-6 \\
6-12\end{array}$ & $\begin{array}{l}45 \cdot 6 \\
47 \cdot 1\end{array}$ & $\begin{array}{l}57 \cdot 3 \\
59 \cdot 1\end{array}$ & $\begin{array}{l}140 \\
142\end{array}$ & $\begin{array}{l}56 \cdot 8 \\
58 \cdot 5\end{array}$ & $\begin{array}{l}0 \cdot 66 \\
0 \cdot 69\end{array}$ & $\begin{array}{l}0 \cdot 89 \\
0 \cdot 72\end{array}$ & $\begin{array}{l}0 \cdot 151 \\
0 \cdot 139\end{array}$ \\
\hline Farmyard manure & $\begin{array}{c}0-6 \\
6-12\end{array}$ & $\begin{array}{l}46 \cdot 6 \\
49 \cdot 8\end{array}$ & $\begin{array}{l}57 \cdot 0 \\
55 \cdot 7\end{array}$ & $\begin{array}{l}142 \\
140\end{array}$ & $\begin{array}{l}57 \cdot 2 \\
58 \cdot 0\end{array}$ & $\begin{array}{l}0.69 \\
0.70\end{array}$ & $\begin{array}{l}0 \cdot 84 \\
0 \cdot 70\end{array}$ & $\begin{array}{l}0 \cdot 140 \\
0 \cdot 132\end{array}$ \\
\hline Municipal compost & $\begin{array}{c}0-6 \\
6-12\end{array}$ & $\begin{array}{l}48 \cdot 4 \\
47 \cdot 6\end{array}$ & $\begin{array}{l}55 \cdot 9 \\
57 \cdot 0\end{array}$ & $\begin{array}{l}142 \\
140\end{array}$ & $\begin{array}{l}57 \cdot 3 \\
57 \cdot 2\end{array}$ & $\begin{array}{l}0 \cdot 68 \\
0 \cdot 70\end{array}$ & $\begin{array}{l}0 \cdot 78 \\
0 \cdot 72\end{array}$ & $\begin{array}{l}0 \cdot 130 \\
0 \cdot 129\end{array}$ \\
\hline Untreated control & $\begin{array}{c}0-6 \\
6-12\end{array}$ & $\begin{array}{l}50 \cdot 0 \\
48 \cdot 6\end{array}$ & $\begin{array}{l}56 \cdot 4 \\
57 \cdot 8\end{array}$ & $\begin{array}{l}143 \\
145\end{array}$ & $\begin{array}{l}55 \cdot 5 \\
56 \cdot 1\end{array}$ & $\begin{array}{l}0.60 \\
0.60\end{array}$ & $\begin{array}{l}0.59 \\
0 \cdot 60\end{array}$ & $\begin{array}{l}0 \cdot 118 \\
0 \cdot 113\end{array}$ \\
\hline
\end{tabular}

* On oven-dry basis. † On air-dry basis.

there has been a marked gain in both carbon and nitrogen, especially in the earlier years, the soil now containing more than twice as much organic matter as most of the other plots ${ }^{2}$. Similar results on the increase in nitrogen content of farmyard manure plots cropped continuously with wheat and barley have been observed at Woburn ${ }^{3}$. An improvement in the nitrogen status of soils following the addition of farmyard manure to soil even under tropical conditions has recently been shown by Dhar and Mukerji ${ }^{4}$; according to these authors, "the carbonaceous substances from the decomposition of organic manures assist in the fixation and conservation of soil nitrogen ${ }^{5}$.

On the other hand, it has been frequently contended. that every soil, depending on a number of complex and interlocked factors, mostly climatic, has more or less definite organic matter and nitrogen status and that it is, therefore, scarcely worth while to attempt to maintain the soil nitrogen and organic matter above certain percentages ${ }^{6-9}$. The foregoing observations would suggest, however, that by the application of bulky organic manures these constituents can, within limits, be maintained at higher levels and within an expense that may be justifiable in terms of crop rotation. In analysing the results of fifty. years of field experiments at the Woburn Experimental Station, Russell and Voelcker have recently come to the conclusion that soil impoverishment under continuous cropping can best be prevented by a combination of farmyard manure with crop rotation ${ }^{3}$.

Humic manures are generally slow-acting and have, in consequence, a much higher residual effect as compared with the immediately available commercial fertilizers. With a deep-rooted crop such as cotton, therefore, their application may not be advisable if their full value is to be utilized. But if they are applied to a previous surface-rooted crop in the rotation they will not only benefit that crop but also have their characteristic effect on the deeper soil layers by the time the turn of the cotton crop comes. This fact has been fully borne out by the work at Indore, where (i) successive application of compost has given consistently high yields with cotton over a period of years, and (ii) in rotation experiments,

TABLe 2. PhRCentage INCREASE IN CARBON AND NITROGEN OVER UNMANURED PLOTS.

\begin{tabular}{|l|c|c|c|c|}
\hline \multirow{2}{*}{ Period of sampling } & \multicolumn{2}{|c|}{ Carbon } & \multicolumn{2}{c|}{ Nitrogen } \\
\cline { 2 - 4 } & Surface soil & Subsoil & Surface soil & Subsoil \\
\hline October 1940 & $\mathbf{4 2 \cdot 4}$ & $18 \cdot 3$ & $\mathbf{1 8 \cdot 6}$ & $\begin{array}{l}17 \cdot 7 \\
\text { July 1942 }\end{array}$ \\
February 1943 & $\mathbf{6 4} \cdot 1$ & $33 \cdot 3$ & $69 \cdot 6$ & $43 \cdot 5$ \\
& & $33 \cdot 9$ & $35 \cdot 4$ & $19 \cdot 6$ \\
\hline
\end{tabular}

compost application to the previous crop has always benefited the succeeding cotton crop.

Agronomic practice hitherto has largely been directed towards determining what manures should be applied to each particular crop. The experience with the permanent manurial plots, however, suggests that it would be more beneficial to manure with the object solely of building up the general fertility of the soil, so as to take care of all crops in the rotation and thus conserve the natural resources of the soil and, in some measure, even improve on them.

${ }^{1}$ Tamhane, V. A., and Sreenivasan, A., Curr. Sci., 12, 135 (1943).

${ }^{2}$ Russell, E. J., and Watson, D. J., Imp. Bureau of Soil Sci., Tech. Commn., 40, 50 (1940).

${ }^{3}$ Russell, E. J., and Voelcker, J. A., "Fifty Years of Field Experiments at the Woburn Experimental Station" (London: Longmans, 1936), 322 .

${ }^{4}$ Dhar, N. R., and Mukerji, S. K., NATURE, 138, 1060 (1936).

${ }^{5}$ Dhar, N. R., NATURE, 151, 590 (1943).

'Russell, J. C., J. Amer. Soc. Agron., 19, 380 (1927).

${ }^{7} J$ enny, H., J. Amer. Soc. Agron., 20, 900 (1928) ; Soil Sci., 29, 193 (1930).

${ }^{8}$ Sahasrabuddhe, D. L., Proc. Nat. Inst. Sci., India, 3, 139 (1937).

"Mohr, E. C. J., cited from S. A. Waksman's "Humus" (London: Baillière, Tindall and Cox, 1938), 2nd edit., 258.

\section{RELATION BETWEEN BODY-SIZE, WAKING ACTIVITY, SIZE OF EYE- BALLS, AND THE ORIGIN OF SOCIAL LIFE IN THE PRIMATES}

\author{
By Prof. M. F. ASHLEY MONTAGU
}

Hahnemann Medical College and Hospital, Philadelphia.

THE demonstration of significant, that is to say functional, interrelations between characters of size, morphology, physiology, and social behaviour has not, to my knowledge, hitherto been made for any group of the order of Primates, including man. In the present communication I should like to report what seems to be the invariable association of four such distinctive characters which are operative throughout the order.

Commencing with an examination of the most primitive members of the order of Primates, the lemurs, we find that they fall into two groups; one is practically completely nocturnal in its habits, sleeping by day and spending most of its waking hours during the night, while the other is mainly diurnal, being almost entirely active by day alone. Like most Primates, all lemurs are arboreal creatures, though the larger lemurs, particularly of the genus Lemur, spend a good deal of time among the rocks. Now, it is a striking fact that the lemurs of small 
body-size are all, unexceptionally, the most definitely nocturnal in their habits, while those of larger size are almost entirely diurnal. This in itself is an interesting association. It would also appear that the small nocturnal lemurs have larger eyeballs than the larger diurnal lemurs. Finally, the small nocturnal lemurs live either in pairs or in single families, while the larger diurnal lemurs tend to live in small groups which contain the members of at least one other family.

Since the lemurs represent the most primitive, as well as the oldest, type of Primates, being, indeed, best regarded as a relict group, it may reasonably be assumed that they preserve the social habits of even earlier ancestral Primates. The point is not very important, but it is worth mention because it is known that the earliest Primates were not much larger than small rats, and from this-together with the evidence cited in this communication-it may be inferred that they were probably nocturnal in their habits, and lived in pairs or single families, as do the closely related primatoid menotyphlous insectivores (for example, Tupaiidæ) to this day.

The evidence provided by the lemurs suggests that small arboreal Primates are better able to survive when they are active at night than they are when they are active during the day. Large eyes provide them with the necessary visual power to pursue their nocturnal activities, and these activities can most effectively be pursued in a solitary manner or in pairs or in small family groups. These seem to be the facts for the lemurs.

The reverse conditions seem to be equally closely connected. Now, what are the facts for the remaining suborders and families of Primates? Are these facts or is this association of conditions corroborated by the conditions existing in any other group of Primates? It may be said at once that the evidence is strikingly corroborative, and where it is exceptional, very enlightening.

The exception to the rule of having all four variables positively correlated is provided by a single family among the Platyrrhini or Old World monkeys, the Hapalidæ, consisting of the marmosets and tamarins. These animals are about the size of a small squirrel, but they all have small or medium-sized eyes, are diurnal in their habits, and are said to live in pairs or in single families. The two important correlations are here ( 1 ) between body size and the habit of living in pairs or in single families, and (2), between diurnal activities and small or medium-sized eyes. I shall return to a discussion of the significance of these facts presently. Meanwhile, we must be grateful to Nature for providing us with exceptional cases, for these often serve to throw light on the relative importance of variables which are otherwise too closely correlated to lend themselves to the necessary separation and analysis.

Finally, and most significantly, among the ten genera of the family Cebidæ (South American monkeys) embracing some ninety-three different species, the species of smallest size (embracing ten species) all belong to the same genus Aotes, the douroucoulis or night-monkeys. These are the only monkeys, among the Cebidæ, which have large eyes, are nocturnal in their habits, and live in pairs or in single families. They are about the size of a squirrel.

All other Primates of the platyrrhine and catarrhine series are of relatively large body-size, with small or medium-sized eyes, are diurnal in their activities, and live in communities or bands. (By a community or band is meant a group consisting of the members of two or more families.)

We have here, then, an almost perfect correlation between (1) body-size, (2) kind of primary social group, (3) waking or sleeping activity habits, and (4) size of eyes.

Small Primates are likely to have large eyes, to be nocturnal, and to live either in solitude, in pairs, or in small family groups. Large Primates are likely to have small or medium-sized eyes, to be diurnal, and to live in bands or communities.

The conditions existing among the marmosets indicate that when small Primates are diurnal their eyes are small or of medium size, and that they retain their habit of living in pairs or in single families.

It need scarcely be pointed out here that even a complete positive correlation does not necessarily imply a causal relationship between the variables found in association. Such an association may be due to still other conditions, and it is a safe general rule to assume that this is the case until erery effort has been exhausted to prove it so. In the present case, in virtue of the nature of the data, such attempts to prove the existence of significant additional conditions are not readily feasikle. Our task must therefore lie in an attempt to educe the order of most probable relationship existing ketween the four variables we have noted. In this we are greatly assisted by the apparently aberrant conditions found among the marmosets. From the latter it appears that body size is directly associated with small social groups limited to a single pair or a family, while size of eyes is most directly associated, as would be expected, with type of waking activ ity.

To conclude, then, the evidence suggests that increase in body size (and, presumably, weight) may have been a potent factor in releasing the early Anthro. poidea from their crepuscular halits, $\mathrm{k} y$ enabling them to hold their own against most aggressors, and that this together with the potentialities released by the assumption of a diurnal life led to the development of more extended social relations with animals of their orn species. It is perhaps worth pointing out that this is not a speculation, but an interpretation of facts to which a high degree of probability is attached.

A fuller account of these tindings will be published in the American Anthropologist.

\section{ADVERTISEMENT OF PROPRIETARY MEDICINES}

"M ASS OBSERVATION" has issued the results of their investigation among their national panel of voluntary informants of he attitude of these informants to patent medicines. These informants do not represent a typical cross-section of the population, but the majority of them are dissatisfied with the present position and ask for further Government control of the price, sale and advertisement of such products, because they make ex ggerated claims, play upon the fears of illness and prevent people from going to a medical man, so that illnesses which might be recognized early, and arrested, become chronic. These informants do not, on the other hand, wish to see medically approved remedies removed from the market.

Emphasis is given to this report by an annotation in the British Medical Journal (Sept. 25 , .943, p. 398) which discusses the experiments performed by Ivy, 